\title{
Role of Physiotherapy in Pre and Post Orthopedic Surgery
}

\author{
Md Monoarul Haque ${ }^{1 *}$ and Md Ashrafuzzaman ${ }^{2}$ \\ ${ }^{1}$ Publication Secretary, Bangladesh Physiotherapy Association, Bangladesh \\ ${ }^{2}$ Master of Public Health, ASA University Bangladesh
}

Submission: July 20, 2016; Published: August 10, 2016

*Corresponding author: Md Monoarul Haque, Publication Secretary, Bangladesh Physiotherapy Association, Bangladesh.

\section{Editorial}

Physiotherapy is a medicine today or tomorrow. As noncommunicable diseases like diabetes, stroke, arthritis increase demand of physiotherapy also in increasing trend. On the contrary popularity and urgency of orthopedic surgery is increasing day by day in our country. Physiotherapy and orthopedic surgery is thought to be the both aspect of same coin; one cannot succeed without other. A good physiotherapist must have sound knowledge on orthopedic surgery and orthopedic surgeon should have a good physiotherapist to deal musculoskeletal injured patient as well as get better result and back to the patient in near normal life. Physiotherapy is a specialized branch of medicine and WHO recognized it independent first contact medical practitioner. In Bangladesh now a day's road traffic accident is common phenomena. Every day we observe it in print and electronic media. In this circumstance orthopedic surgeon has to pass busy time with the injured patients. Not only has that occupational hazard made this situation vivid indeed. We know orthopedic surgeon mainly deals with fracture and dislocation by surgical measure but if we want to make the limb/injured part active and rapid recovery definitely need physiotherapy and rehabilitation services. This is why physiotherapist is included in multidisciplinary team. Before surgery muscle power testing is an important matter if we get to better result or fruitful orthopedic surgery or minimize postoperative complication or rapid rehabilitation. Usually muscle weakness, joint stiffness, contracture is seen after operation/plaster due to lack of physiotherapy. Early initiation of physiotherapy is needed to prevent complication. There is a tendency to develop bed sore in case of spinal cord injury patient due to immobility. It can be preventable by altering position in every two hours. Mutual understanding and professional cooperation is required between physiotherapist and orthopedic surgeon for betterment of patient. Referring system should be developed. In some case like sports injuries physiotherapist play vital role as well as act as first contact medical person where road traffic accident orthopedic surgeon works as first contact professional. In our country we are lacking behind referring patient to other medical practitioner. Finally, to come out better outcome orthopedic surgery and physiotherapy can move together by cooperating each other. 